\title{
MCF-7 Breast Cancer Cells Transfected with Protein Kinase C- $\alpha$ Exhibit Altered Expression of Other Protein Kinase C Isoforms and Display a More Aggressive Neoplastic Phenotype
}

\author{
D. Kirk Ways, * Cynthia A. Kukoly, ${ }^{\star}$ James deVente, ${ }^{\ddagger}$ Jerry L. Hooker, ${ }^{*}$ Winifred O. Bryant, ${ }^{\circ}$ Karla J. Posekany, ${ }^{\ddagger}$ \\ Donald J. Fletcher, ${ }^{5}$ Paul P. Cook, ${ }^{*}$ and Peter J. Parker" \\ Departments of $*$ Medicine, ${ }^{\ddagger}$ Microbiology/Immunology, and ${ }^{8}$ Anatomy/Cell Biology, East Carolina University School of Medicine, \\ Greenville, North Carolina 27858; and "Imperial Cancer Research Fund, Protein Phosphorylation Laboratory, London WC2A 3PX, \\ United Kingdom
}

\begin{abstract}
Increased protein kinase $\mathrm{C}$ (PKC) activity in malignant breast tissue and positive correlations between PKC activity and expression of a more aggressive phenotype in breast cancer cell lines suggest a role for this signal transduction pathway in the pathogenesis and/or progression of breast cancer. To examine the role of PKC in the progression of breast cancer, human MCF-7 breast cancer cells were transfected with PKC- $\alpha$, and a group of heterogenous cells stably overexpressing PKC- $\alpha$ were isolated (MCF-7-PKC$\alpha)$. MCF-7-PKC- $\alpha$ cells expressed fivefold higher levels of PKC- $\alpha$ as compared to parental or vector-transfected MCF7 cells. MCF-7-PKC- $\alpha$ cells also displayed a substantial increase in endogenous expression of PKC- $\beta$ and decreases in expression of the novel $\delta$ - and $\eta$-PKC isoforms.

MCF-7-PKC- $\alpha$ cells displayed an enhanced proliferative rate, anchorage-independent growth, dramatic morphologic alterations including loss of an epithelioid appearance, and increased tumorigenicity in nude mice. MCF-7-PKC$\alpha$ cells exhibited a significant reduction in estrogen receptor expression and decreases in estrogen-dependent gene expression. These findings suggest that the PKC pathway may modulate progression of breast cancer to a more aggressive neoplastic process. (J. Clin. Invest. 1995. 95:1906-1915.) Key words: PKC isoforms • vimentin - estrogen receptor • anchorage independent $\cdot$ tumorigenicity

\section{Introduction}

Protein kinase $\mathrm{C}(\mathrm{PKC})^{1}$ is a gene family consisting of several subfamilies (conventional: $\alpha, \beta_{\mathrm{I}}, \beta_{\mathrm{II}}, \gamma$, novel: $\delta, \epsilon, \theta, \eta$; and

This work was presented in part at the American Federation for Clinical Research in Baltimore, MD, 29 April-2 May 1994 and published in abstract form (1994. Clin. Res. 42:206a).

Address correspondence to Dr. Kirk Ways, Department of Medicine, Section of Endocrinology \& Metabolism, East Carolina University School of Medicine, Greenville, NC 27858. Phone: 919-816-2567; FAX 919-816-3096.

Received for publication 26 September 1994 and in revised form 29 November 1994.

1. Abbreviations used in this paper: CAT, chloramphenicol acetyltransferase; MDR, multidrug resistant; PKC, protein kinase C; TPA, tetradecanoyl-13-phorbol acetate; vit-tk-CAT, estrogen-responsive vitellogenin promoter-CAT reporter construct.

J. Clin. Invest.

(C) The American Society for Clinical Investigation, Inc.

0021-9738/95/04/1906/10 \$2.00

Volume 95, April 1995, 1906-1915 atypical: $\lambda, \zeta, \iota)$ that lie on signal transduction pathways regulating growth and differentiation in a large and diverse group of cell types $(1,2)$.

A role for members of the PKC gene family in regulating growth and differentiation of breast cancer has been suggested by several separate observations. In extracts prepared from samples derived from patients undergoing breast biopsy, PKC activity was elevated in malignant breast tumors relative to normal breast tissue (3). In cultured breast cancer cell lines, a positive correlation also existed between PKC activity and the more biologically aggressive estrogen receptor negative phenotype $(4,5)$. In the MCF-7 and other breast cancer cell lines, phorbol ester treatment that induced downregulation of PKC activity inhibited growth and enhanced expression of parameters associated with a more differentiated phenotype (6-9). Studies examining the effects of bryostatin-1 and tetradecanoyl-13-phorbol acetate (TPA) on growth of breast cancer cell lines have implicated a role for the conventional PKC- $\alpha$ isoform in mediating TPA-induced growth inhibition (8). Desensitization to phorbol ester-induced growth inhibition has been associated with increases in PKC content and activity (6). Additionally, inhibitors of PKC-associated kinase activity, such as the staurosporine analogue UCN-01, inhibit growth of the MCF-7 cell (10). These findings suggest that aberrations in the PKC signal transduction pathway may be involved in the pathogenesis and/or progression of breast cancer, and that PKC may be involved in the regulation of estrogen receptor expression, a parameter of prognostic and therapeutic importance.

Given the possible role for the PKC signal transduction pathway, specifically PKC- $\alpha$, in the pathogenesis of breast cancer, we directly examined the effects of stably overexpressing PKC- $\alpha$ on the MCF-7 human breast cancer cell line. Stable overexpression of PKC- $\alpha$ led to an enhanced rate of proliferation, more efficient anchorage-independent growth, dramatic alterations in cellular morphology manifested by loss of an epithelioid appearance with a marked increase in vimentin expression, a marked decrease in estrogen receptor mRNA transcripts and estrogen-dependent gene expression, enhanced tumorigenicity with metastatic capacity when injected into nude mice, and significant increases in the endogenous expression of PKC- $\beta$ accompanied by decreases in the content of PKC- $\eta$ and $-\delta$.

These findings demonstrate that overexpression of PKC$\alpha$, either directly or indirectly, possibly via increases in the endogenous expression of PKC- $\beta$ or decreases in the $\eta$ or $\delta$ isoforms, leads to the acquisition of a more fully transformed phenotype in the MCF-7 breast cancer cell, and provide further evidence for a possible role of the PKC signaling pathway in the pathogenesis and/or progression of breast cancer and regulation of estrogen receptor status. 


\section{Methods}

Cell culture. MCF-7 cells were purchased from the American Type Culture Collection (Rockville, MD) and grown in DME supplemented with $2 \mathrm{mM}$ glutamine, $10 \mathrm{mM}$ Hepes, $10 \%$ FCS, $50 \mathrm{U} / \mathrm{ml}$ penicillin, and $50 \mu \mathrm{g} / \mathrm{ml}$ streptomycin. For cell growth experiments, $7.5 \times 10^{3}$ cells $/ \mathrm{ml}$ were incubated in 24-well plates. Cell viability was assessed using trypan blue exclusion. Counting of cells was performed using a Coulter counter (Coulter Corp., Hialeah, FL).

Generation of MCF-7 cells overexpressing PKC- $\alpha$. Bovine PKC- $\alpha$ (11) was subcloned into the $\mathrm{pSV}_{2} \mathrm{M}(2) 6$ plasmid $(20 \mu \mathrm{g})$ and cotransfected with $2 \mu \mathrm{g}$ pMAM-neo plasmid (Clonetech, Palo Alto, CA) by calcium phosphate precipitation. The $\mathrm{pSV}_{2} \mathrm{M}(2) 6$ vector was generously provided by Dr. Marilyn Sleigh (Commonwealth Scientific and Industrial Research Organization, Sydney, Australia [12]). $72 \mathrm{~h}$ after transfection the cells were incubated in $0.75 \mathrm{mg} / \mathrm{ml} \mathrm{G418.} \mathrm{After} \mathrm{a} \mathrm{6-}$ wk selection period, multiple clones of cells overexpressing PKC- $\alpha$ (MCF-7-PKC- $\alpha$ ) and vector without the PKC insert were detected. The results presented herein are derived from pooling these separate clones into heterogeneous groups of vector- or PKC- $\alpha$-transfected cells. Although transfected PKC- $\alpha$ is under control of a metallothionein promoter, cells stably transfected with this construct displayed marked phenotypic changes and overexpressed the $\alpha$ isoform approximately fivefold in the absence of supplemental heavy metals beyond the quantities contained in FCS (see Results). Because of the basal induction of PKC- $\alpha$, experiments were done in the absence of further heavy metal supplementation. The MCF-7-PKC- $\alpha$ and vector-transfected cells have maintained stable phenotypic characteristics over a 9-mo period.

$P K C$ activity and Western blot analysis. Cytosolic, solubilized particulate, or whole-cell solubilized extracts, were prepared as previously described (13) and used for quantitation of PKC activity and Western blot analysis. Protein content was determined by the Bradford technique (14). Using equal protein concentrations $(10 \mu \mathrm{g})$, PKC activity was assessed as previously described (15) with histone III-s, a peptide corresponding to residues 4-14 of myelin basic protein (16), and a serinesubstituted PKC- $\delta$ pseudosubstrate site peptide (15) as substrates. PKC activity was defined as the difference in cpm incorporated into the substrates in the absence and presence of TPA and phosphatidylserine.

Western blot analysis was done as previously described using antisera specific for the $\alpha, \beta, \epsilon$, and $\zeta$ isoforms $(13,15)$. Antipeptide antiserum against the carboxy terminus of PKC- $\eta$ (INQDEFRNFSYVSPELQL) was prepared and used in this study at a dilution of 1:1,000. This antiserum recognized a protein doublet at approximately the predicted molecular weight for PKC- $\eta$ and a slightly lower molecular weight species. The specificity of these proteins was confirmed by the ability of the immunizing peptide to abolish detection of these bands. A separate PKC- $\eta$ antiserum, purchased from Santa Cruz Biotechnology, Inc., (Santa Cruz, CA) gave identical results to those obtained using our $\eta$ antipeptide antibody. Antiserum to PKC- $\delta$ was purchased from Transduction Labs (Lexington, $\mathrm{KY}$ ) and was used as per their recommendations. Detection was performed using goat anti-mouse antiserum and enhanced chemiluminescence (15). Densitometric analysis of the autoradiograms was performed using a laser densitometer (Ultrascan XL; Pharmacia LKB Biotechnology, Inc., Piscataway, NJ).

Northern blot analysis. RNA was extracted using a single-step acid guanidinium thiocyanate-phenol extraction technique (17). RNA (20 $\mu \mathrm{g}$ ) was electrophoresed, transferred to nylon filters, and hybridized to random primer labeled cDNA probes (18). Ethidium bromide staining was used to confirm the integrity of the RNA and assess the equivalency of loading. The probes used for PKC $-\beta,-\eta$, and $-\delta$ were isolated by P. Parker and represent the full length cDNAs. The vimentin cDNA was generously provided by Dr. Susan Rittling (Rutgers University). Probes for the estrogen receptor, cathepsin D, and pS2 genes were purchased from the American Type Culture Collection.

Microscopy. Cells maintained in culture were photographed at a magnification of 400 with an inverted microscope (Diaphot; Nikon, Inc., Melville, NY). For structural analysis, cells were fixed for $30 \mathrm{~min}$ in $2.5 \%(\mathrm{vol} / \mathrm{vol})$ glutaraldehyde and $0.2 \mathrm{M}$ phosphate buffer $(\mathrm{pH}$
7.4). After postfixation in $1 \%$ (wt/vol) osmium tetroxide, cells were dehydrated through a graded series of alcohol and propylene oxide and embedded in Epon (Electron Microscopy Sciences, Fort Washington, PA). Thin sections $(<90 \mathrm{~nm})$ were stained with uranyl acetate and lead citrate and examined with an electron microscope (1200 EX; JEOL USA Inc., Peabody, MA).

Cell cycle analysis. $30 \mathrm{~min}$ before harvesting, cells were incubated with $10 \mu \mathrm{M}$ bromodeoxyuridine. Cells were then trypsinized, washed, resuspended in PBS, and fixed in $70 \%$ ethanol at $4^{\circ} \mathrm{C}$ for $30 \mathrm{~min}$. The fixed cells were treated at room temperature for $6 \mathrm{~min}$ with $6 \mathrm{~N} \mathrm{HCL}$ containing $0.5 \%$ Triton X-100. After washing with PBS, the cells were resuspended in serum-free RPMI 1640 media and incubated for 15 min at room temperature with FITC-conjugated antibromodeoxyuridine antiserum (Becton Dickinson Immunocytometry Systems, Mountain View, CA). The samples were washed, resuspended in $50 \mu \mathrm{g} / \mathrm{ml}$ propidium iodide contained in a citrate buffer, and immediately analyzed on a flow cytometer (Facscan ${ }^{\star}$; Becton Dickinson Immunocytometry Systems). Linear red and green fluorescence and logarithmic forward and side scatter signals were obtained on $10^{4}$ cells. For statistical analysis, polygonal regions were drawn on a propidium iodide versus bromodeoxyuridine 2-parameter histogram display defining cells in $G_{0} / G_{1}, S$, and $\mathrm{G}_{2} \mathrm{M}$ phases. The percentage of cells falling within these regions was calculated using the Facscan ${ }^{\otimes}$ statistical analysis package (Becton Dickinson Immunocytometry Systems) and normalized to $100 \%$.

Transfection and reporter construct analysis. Cells were transiently transfected using calcium phosphate precipitation with $3 \mu \mathrm{g} \mathrm{p}$-cytomegalovirus $\beta$-galactosidase plasmid (Clonetech Laboratories, Palo Alto, CA ), $4 \mu$ g estrogen-responsive vitellogenin promoter-chloramphenicol acetyltransferase reporter construct (vit-tk-CAT), and $13 \mu \mathrm{g}$ of carrier DNA. After an overnight incubation, the cells were washed and grown in media with $10 \%$ FCS. $40 \mathrm{~h}$ later, $\beta$-galactosidase and CAT activity were analyzed by standard methodologies and CAT measurements were normalized to $\beta$-galactosidase activity. The estrogen-responsive, vit-tkCAT construct was kindly provided by Dr. Gerhardt Ryffel (Kernforschungszentrum, Karlsruhe Institut für Genetik und Toxikologie [19]).

Growth in soft agar. In a 35-mm dish, $1 \mathrm{ml}$ of $0.6 \%$ agar in DME with $10 \%$ FCS was plated and allowed to harden. Top agar, $0.36 \%$, containing $10^{3}$ cells $/ \mathrm{ml}$ was layered over the hardened agar. Cultures were incubated at $37^{\circ} \mathrm{C}$ in $5 \% \mathrm{CO}_{2}$ for $10-12 \mathrm{~d}$. Colonies $>50$ cells were visually enumerated.

Tumor and metastatic evaluation in nude mice. BALB/c nu/nu female mice, 6-8 wk old, were inoculated with $7 \times 10^{6}$ cells in 0.1 $\mathrm{ml}$ of PBS into the mammary fat pad. Because of the rapid primary tumor growth in mice inoculated with the MCF-7-PKC- $\alpha$ cells, animals were killed only $4 \mathrm{wk}$ after inoculation. Tumor volume was assessed by measuring tumor size in three dimensions. Histologic examination of the primary tumor and other organs was done using hematoxylin and eosin staining.

\section{Results}

Overexpressing of $P K C-\alpha$ increased $P K C$ activity and altered expression of endogenous PKC isoforms. MCF-7 cells were cotransfected with the neomycin resistance plasmid and either the $\mathrm{pSV}_{2} \mathrm{M}(2) 6$ vector without the insert or containing a fulllength cDNA encoding PKC- $\alpha$. Cells harboring the neomycin resistance gene were identified by selection in G418. Rather than single cell cloning, a mixed group of neomycin-resistant cells was isolated. A heterogenous population of transfected cells was used to minimize the possible artifacts that can be associated with single cell cloning. Analysis of PKC- $\alpha$ expression is shown in Fig. 1. As compared to either parental MCF7 cells or cells stably transfected with the neomycin gene and vector without the PKC insert, PKC- $\alpha$ was overexpressed approximately three- to fivefold, as assessed by densitometric 


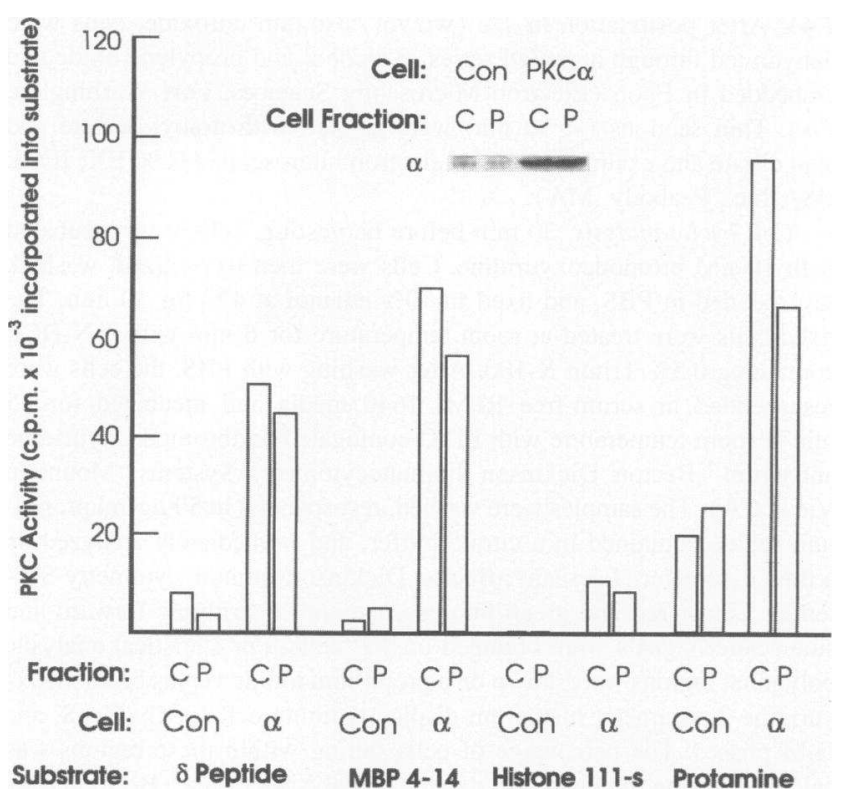

Figure 1. PKC- $\alpha$ content, and PKC activity in MCF-7-PKC- $\alpha$. Equal amounts of protein $(40 \mu \mathrm{g})$ derived from cytosolic $(C)$ and solubilized particulate $(P)$ fractions from parental (con) and MCF-7-PKC- $\alpha$ $(P K C-\alpha)$ cells were subjected to Western blot analysis using PKC- $\alpha$ antiserum (inset). PKC activity of the same cells is shown below. The substrates used are indicated beneath the figure. PKC activity is defined as the difference in cpm incorporated into substrate in the absence and presence of phosphatidylserine and TPA in parental (con) and MCF$7-\mathrm{PKC}-\alpha(\alpha)$ cells. These experiments were repeated on three separate occasions with similar results.

analysis, in the cells stably transfected with this isoform (MCF$7-\mathrm{PKC}-\alpha$ cells $)$. Corroborating the increased content of this isoform in PKC- $\alpha$ cells was a 5-16-fold increase, depending upon the substrate used, in PKC activity in the MCF-7-PKC$\alpha$ cells as compared to the parental MCF-7 cell (Fig. 1).

Endogenous expression of other PKC isoforms in MCF-7PKC- $\alpha$ cells was examined by Western blot analysis (Fig. 2 $A$ ). Parental MCF-7 cells contained readily apparent amounts of $\alpha, \epsilon, \delta, \eta$ and $\zeta$ isoforms (Figs. 1 and 2). Using a $\beta$ antiserum directed against the $\mathrm{V}_{3}$ region of the molecule, we were unable to detect significant PKC- $\beta$ expression in the parental MCF-7 cell. The PKC- $\eta$ antiserum specifically detected three bands with molecular weights of 86,82 , and $60 \mathrm{kD}$. Relative to the parental MCF-7 cells, MCF-7-PKC- $\alpha$ cells displayed a large increase in protein content of $\beta$ and similar quantities of $\epsilon$ and $\zeta$. Levels of $\delta$ were reduced modestly in MCF-7-PKC- $\alpha$ cells. Levels of the $86-$ and $82-\mathrm{kD}$ proteins detected by the PKC- $\eta$ antiserum were negligible in MCF-7-PKC- $\alpha$ cells. Content of the lower $60-\mathrm{kD}$ protein detected by the $\eta$ antiserum was also substantially reduced in MCF-7-PKC- $\alpha$ cells. The identity of the $60-\mathrm{kD}$ protein and its relation to the predicted molecular weight form of $\eta$ remains unresolved. Densitometric scanning of cytosolic and solubilized particulate fractions subjected to Western blot analysis indicated the following subcellular distribution of PKC isoforms in MCF-7 cells: $\alpha, 65 / 35$ (percentage of total isoform content in cytosolic/solubilized particulate fractions); $\epsilon, 60 / 40 ; \zeta, 52 / 48 ; \eta 86-\mathrm{kD}$ species, $39 / 61 ; \eta 82-\mathrm{kD}$ species, 53/47; and $\eta 60-\mathrm{kD}$ species, $80 / 20$. In MCF-7-PKC- $\alpha$ cells, the cytosolic/solubilized particulate fraction distributions
A
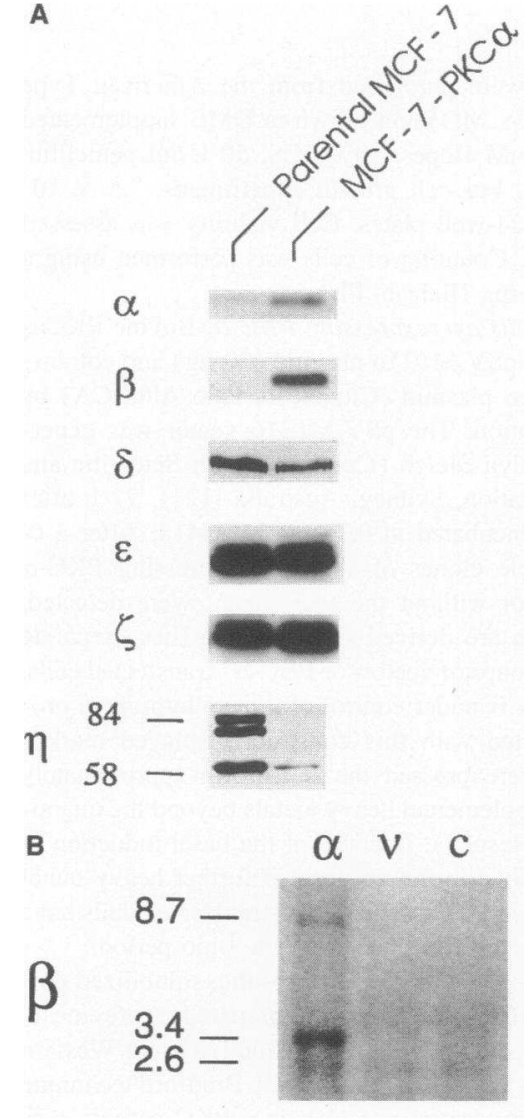

Figure 2. Altered endogenous $\mathrm{PKC}$ isoform content in MCF-7-PKC- $\alpha$ cells. $(A)$ Western blot analysis was performed on equal protein concentrations of whole-cell solubilized fractions derived from parental and MCF-7-PKC- $\alpha$ cells.

The antisera used are indicated (left). Molecular weight standards are shown to the left of the PKC- $\eta$ autoradiogram. Vector-transfected cells displayed identical PKC isoform expression as did parental MCF-7 cells. (B) Northern blot analysis using total RNA (20 $\mu \mathrm{g})$ prepared from parental $(C)$, vector $(V)$, and MCF-7-PKC- $\alpha(\alpha)$ cells was performed with PKC- $\beta,-\eta$, and $-\delta$ DNA probes. The approximate molecular weight of the detected mRNA transcripts is indicated to the side of the autoradiogram. Ethidium bromide $(E t B r)$ staining is shown below the autoradiograms. These experiments were performed on a separate occasions with similar results.

were as follows: $\alpha, 46 / 54 ; \beta, 81 / 19 ; \epsilon, 56 / 44 ; \zeta, 58 / 42$; and $\eta 60-\mathrm{kD}$ species, $60 / 40$. Because of their negligible amounts, PKC- $\beta$ and the $86 / 82-k D$ species of PKC- $\eta$ could not be quantitated in MCF-7 and MCF-7-PKC- $\alpha$ cells, respectively. Because of these changes in the endogenous expression of the $\beta$, $\delta$, and $\eta$ isoforms in MCF-7-PKC- $\alpha$ cells, Northern blot analysis was performed to examine the content of their mRNA transcripts. A concomitant increase in mRNA transcripts for the $\beta$ isoform and decreases in the $\delta$ and $\eta$ isoform mRNA transcripts were noted in the MCF-7-PKC- $\alpha$ cells (Fig. $2 B$ ). Thus, either in a direct fashion or secondary to the phenotypic changes demonstrated in MCF-7-PKC- $\alpha$ cells (see below), PKC- $\alpha$ overex- 

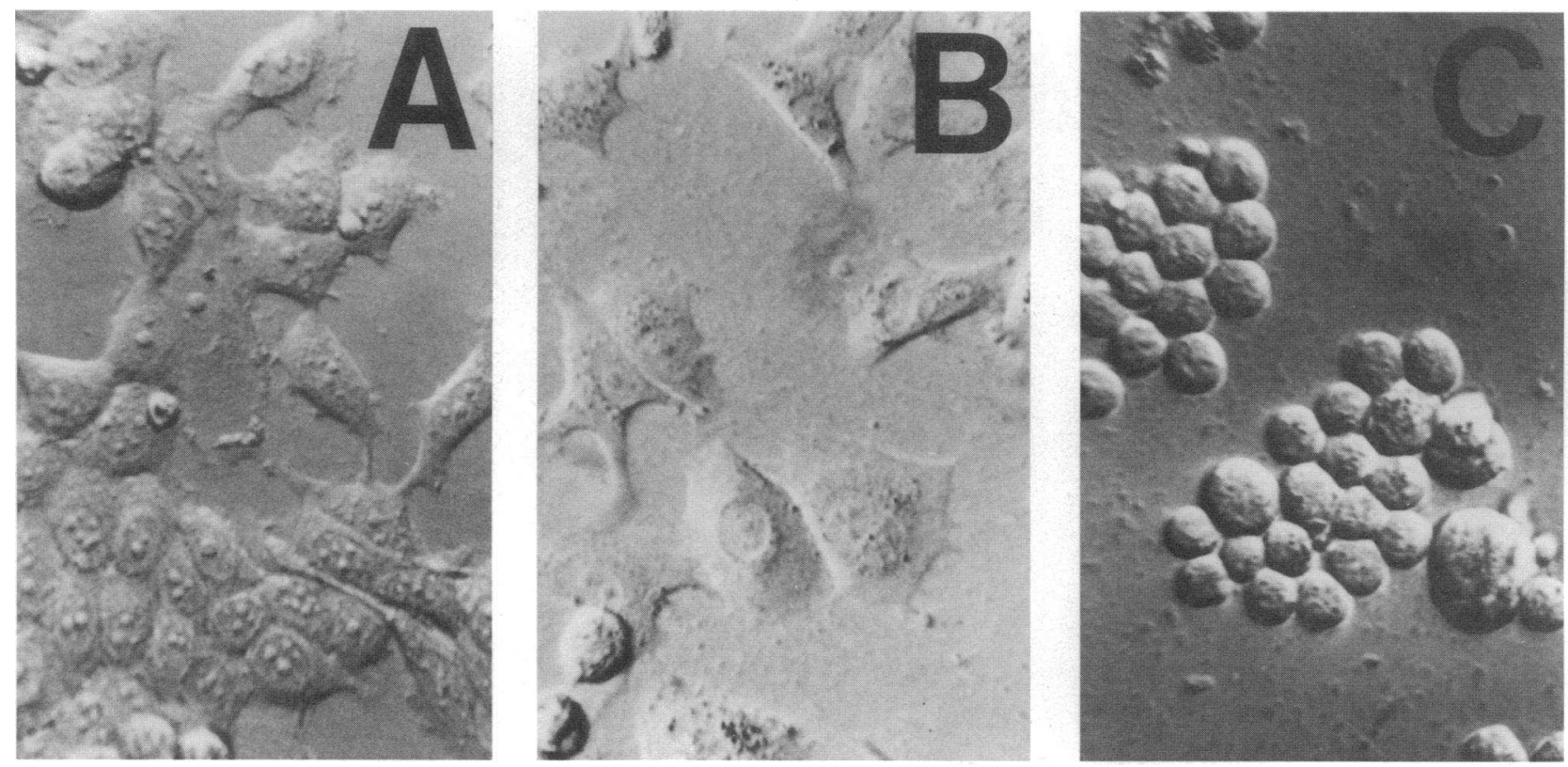

Figure 3. Dissimilar morphology of MCF-7-PKC- $\alpha$ and parental MCF-7 cells. Exponentially growing parental $(A)$, vector-transfected (B), and MCF-7-PKC- $\alpha(C)$ cells were photographed at a magnification of 400 using a Diaphot inverted microscope.

pression modulated expression of other endogenous PKC family members.

Overexpression of PKC- $\alpha$ drastically altered morphology of the MCF-7 cell. MCF-7-PKC- $\alpha$ cells demonstrated dramatic morphologic alterations as compared to parental MCF-7 cells (Fig. 3). Parental and vector-transfected MCF-7 cells displayed an epithelioid appearance growing adherent to the plastic surface (Fig. 3, $A$ and $B$, respectively). In marked contrast, MCF-7PKC- $\alpha$ cells assumed a spherical shape, could proliferate in suspension, especially as cell density increased, and occasionally formed giant cells (Fig. $3 \mathrm{C}$ ). Electron microscopy indicated that parental MCF-7 cells contained primary lysosomal granules (Fig. 4 A, black triangular indicators), while MCF-7-PKC- $\alpha$ cells contained an abundance of secondary lysosomal granules (Fig. $4 B$, thin arrows). The nuclear to cytoplasmic ratio was significantly greater in MCF-7-PKC- $\alpha$ cells. While not observed in MCF-7 cells, areas enriched in intracellular fibrils were noted in MCF-7-PKC- $\alpha$ cells (Fig. 4 B, thick arrows). At a magnification of 50,000 these fibrils had a diameter consistent with intermediate filaments (data not shown), As shown in Fig. $4 C$, Northern blot analysis revealed a dramatic increase in mRNA transcripts for vimentin, an intermediate filament that is not normally expressed in MCF-7 cells (20) and whose expression is a poor prognostic indicator in breast cancer $(21,22)$.

$M C F-7-P K C-\alpha$ cells are estrogen receptor negative and display a loss of estrogen-dependent gene expression. In previous studies an association between increases in PKC activity and decreases in estrogen receptor expression have been noted $(4,5)$. Given this association and the more morphologically aggressive appearance of the MCF-7-PKC- $\alpha$ cell, estrogen receptor status was analyzed (Fig. $5 A$ ). By Northern blot analysis, parental MCF-7 cells were shown to contain transcripts for estrogen receptor mRNA. In contrast, mRNA transcripts for the estrogen receptor were not detected in MCF-7-PKC- $\alpha$ cells. To assess the functional importance of this finding, expression of estrogenresponsive genes and the activity of an estrogen-responsive genes and the activity of an estrogen-responsive reporter construct were analyzed. Expression of estrogen-responsive genes, pS2, and cathepsin D $(23,24)$, were markedly decreased in MCF-7-PKC$\alpha$ cells grown in the presence of $10 \%$ FCS (Fig. 5 A). Activity of the estrogen-responsive vit-tk-CAT reporter construct induced by estrogens contained in $10 \%$ FCS was apparent in parental MCF-7 cells (Fig. 5 B). However, this estrogen-dependent activity was minimal in MCF-7-PKC- $\alpha$ cells. Thus, the MCF7-PKC- $\alpha$ cells share a similar relationship between decreased estrogen receptor expression and increased PKC activity, as has previously been described in clinical samples from patients with breast cancer (4).

MCF-7-PKC- $\alpha$ cells demonstrate a higher proliferative rate and enhanced anchorage-independent growth. MCF-7PKC- $\alpha$ cells proliferated at a higher rate than did parental or vector-transfected cells (Fig. $6 A$ ). As MCF-7-PKC- $\alpha$ increased in density, they detached from the plastic surface and proliferated in suspension (Fig. $6 \mathrm{~B}$ ). The nonadherent population of the MCF-7-PKC- $\alpha$ were viable as assessed by trypan blue exclusion (data not shown). In contrast, parental MCF-7 cells proliferated in an adherent fashion (Fig. $6 \mathrm{~B}$ ). MCF-7PKC- $\alpha$ and parental or vector-transfected cells reached saturation density at $\sim 1.2 \times 10^{6} / \mathrm{ml}$ and $0.5 \times 10^{6} / \mathrm{ml}$, respectively (data not shown). The importance of the higher cell density at confluence in MCF-7-PKC- $\alpha$ cells is somewhat uncertain given the ability of these cells, but not the parental MCF-7 cells, to grow in suspension.

Given the rapid proliferative rate of MCF-7-PKC- $\alpha$ cells and the poor prognostic value in clinical specimens of a high $S$ phase value (25), the proportion of exponentially growing cells in S phase was evaluated. In parental MCF-7 cells, the cells were proportioned as follows: $\mathrm{G}_{0} / \mathrm{G}_{1}: 61 \pm 1.6$; $\mathrm{S}: 23 \pm 1.3$; and $\mathrm{G}_{2} / \mathrm{M}: 16 \pm 1.5(X \pm \mathrm{SEM}, n=10)$. In MCF-7-PKC- $\alpha$ cells, the cell cycle distribution was as follows: $G_{0} / G_{1}: 44 \pm 1.2$; S: $39 \pm 2.4$; and $\mathrm{G}_{2} / \mathrm{M}: 17 \pm 1.5(X \pm \mathrm{SEM}, n=8)$. Thus, MCF$7-\mathrm{PKC}-\alpha$ cells displayed an increase in $\mathrm{S}$ phase cells with a 

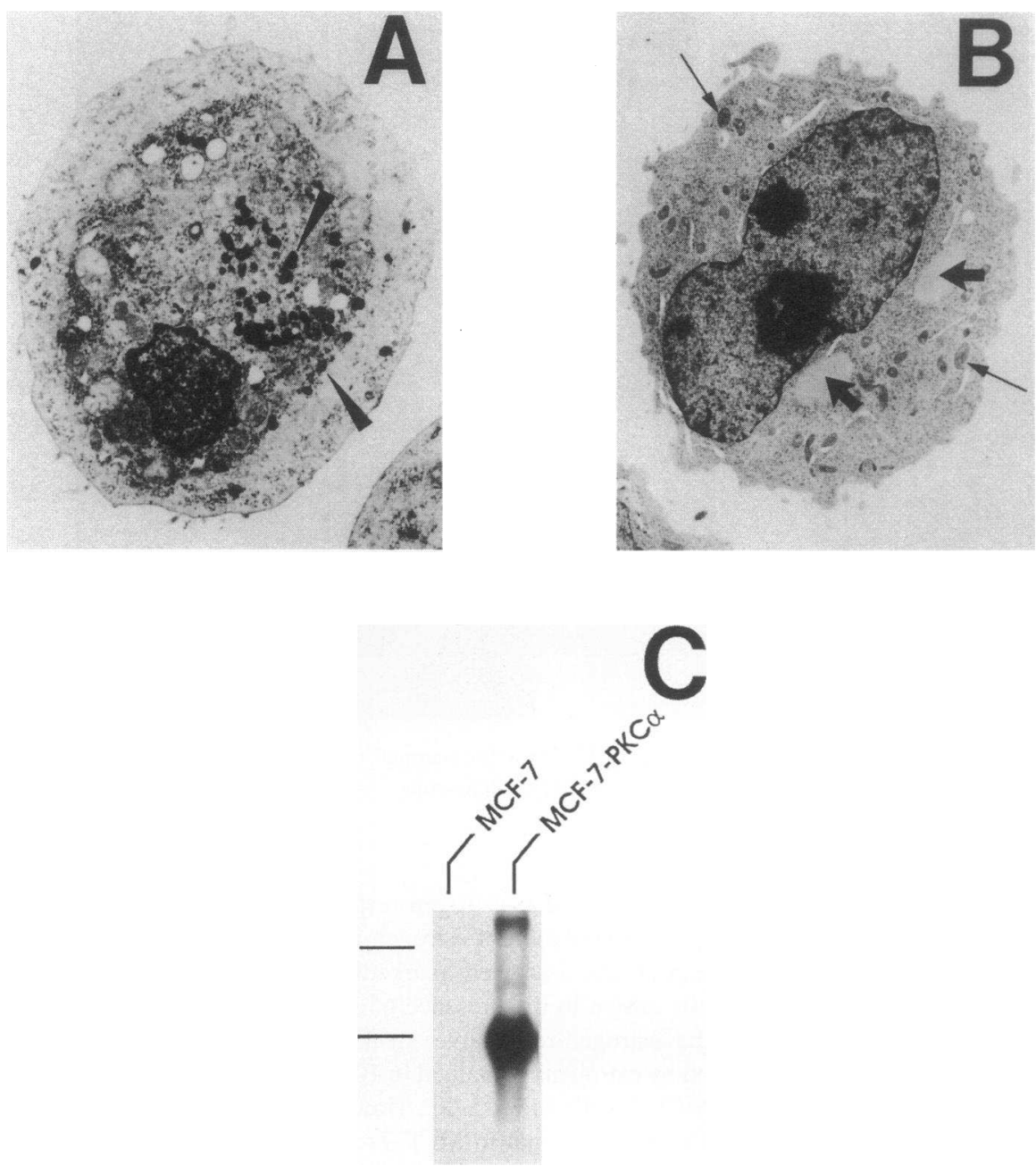

Figure 4. Electron microscopy of MCF-7 and MCF-7-PKC- $\alpha$ cells. Electron microscopy was performed on parental MCF-7 $(A)$ and MCF-7-PKC- $\alpha(B)$ cells at $\times 5,000$. In $A$, the black triangular indicators mark primary lysosomal granules. In $B$, the thin arrows point to secondary lysosomal granules while the thicker arrows are directed at a bundles of intracellular fibrils. Northern blot analysis of vimentin expression in parental MCF-7 and MCF-7-PKC- $\alpha$ cells is shown in $C$. Ethidium bromide staining demonstrated that equivalent amounts of RNA were loaded per lane (data not shown).

concomitant decrease of cells in $\mathrm{G}_{0} / \mathrm{G}_{1}$. Using a two-tailed Student's $t$ test, these differences between the parental MCF-7 and MCF-7-PKC- $\alpha$ cells were statistically significant at a level of $<0.05$.

MCF-7-PKC- $\alpha$ cells readily grew in an anchorage-independent manner in soft agar (Fig. 7). However, under these experimental conditions, parental MCF-7 cells displayed negligible anchorage-independent growth with only a few cell clusters observed and no colonies of $>50$ cells detected (Fig. 7).

$M C F-7-P K C-\alpha$ cells were tumorigenic in nude mice with a propensity to metastasize. When injected into the mammary fat pad, MCF-7-PKC- $\alpha$ cells rapidly formed large primary tumors in all mice by 4 wk postinoculation (Table I). The single mouse that did not form a tumor when inoculated with MCF$7-$ PKC- $\alpha$ cells was inadvertently injected outside the mammary fat pad and into the subcutaneous space. The tumors in mice inoculated with MCF-7-PKC- $\alpha$ cells were well circumscribed and bordered by a thin fibrous tissue network. Histologically, the MCF-7-PKC- $\alpha$ primary tumors were composed of solid sheets of tightly packed, anaplastic, round to polygonal cells with scant basophilic to pale eosinophilic cytoplasm and mild cellular pleomorphism (Fig. 8, $A$ and $B$ ). Marked nuclear pleomorphism, increased content of nucleoli, and numerous mitotic figures were also noted in the primary MCF-7-PKC- $\alpha$ tumors. In contrast, parental MCF-7 cells formed only microscopic, nonpalpable primary tumors in $2 / 10$ animals with no detectable metastases. Western blot analysis of the primary MCF-7-PKC$\alpha$ tumors demonstrated the continued expression of $\alpha, \beta, \delta, \epsilon$, $\eta$, and $\zeta$ isoforms (data not shown). Due to the microscopic size of the tumors in mice injected with parental MCF-7 cells, a direct comparison between the relative in vivo expression of isoforms in parental MCF-7 and MCF-7-PKC- $\alpha$ cells could not be made. In mice inoculated with MCF-7-PKC- $\alpha$ cells, metastases were observed in lymph nodes, lung, and perinephric fat (Table I). Metastases in mice inoculated with MCF-7-PKC$\alpha$ cells were microscopic in size. The full extent of the metastatic potential of the MCF-7-PKC- $\alpha$ cell may have been underestimated because of the relatively short period from inoculation to necropsy ( $4 \mathrm{wk}$ ) that was necessitated by the rapid growth of the primary MCF-7-PKC- $\alpha$ tumor. Given the positive correlation between metastatic capacity and the size of the primary breast tumor (26), it is uncertain whether MCF-7PKC- $\alpha$ cells had a higher metastatic potential simply because of their high growth rate or whether these cells acquired separate biologic programs, rendering them with an intrinsically increased metastatic capacity.

\section{Discussion}

This study demonstrates that human MCF-7 breast cancer cells transfected with and overexpressing PKC- $\alpha$ display enhanced 


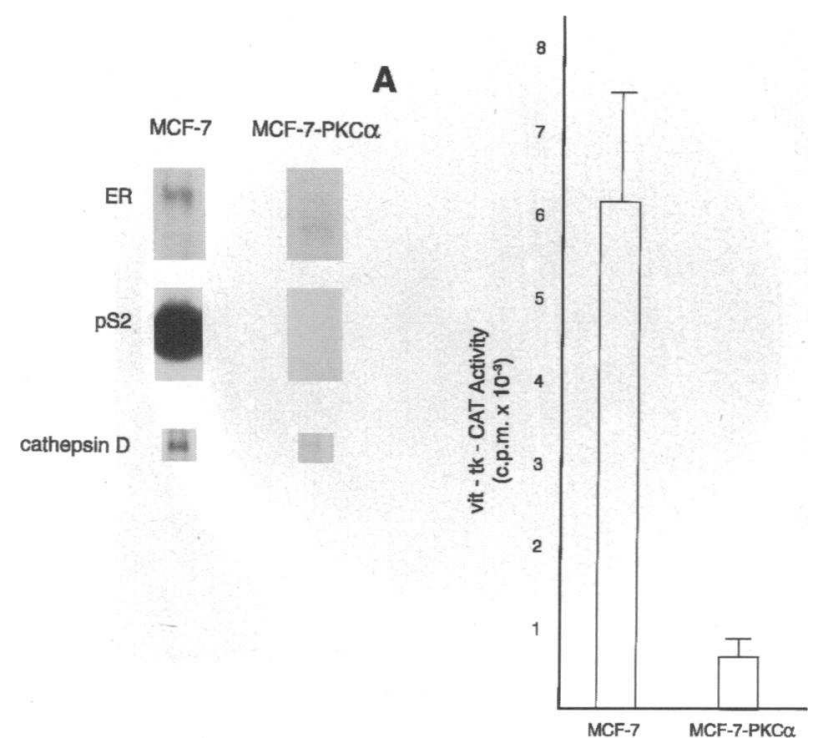

Figure 5. Diminished estrogen receptor content and function in MCF7-PKC- $\alpha$ cells. $(A)$ Total RNA, $20 \mu \mathrm{g}$, prepared from parental and MCF-7-PKC- $\alpha$ cells, was subjected to Northern blot analysis using cDNA probes corresponding to the estrogen receptor $(E R), \mathrm{pS} 2$, and cathepsin D as shown to the left of the autoradiograms. Equivalent amounts of RNA were loaded per lane as assessed by ethidium bromide staining (data not shown). (B) vit-tk-CAT activity normalized to $\beta$ galactosidase measurements (ordinate) was analyzed in parental and MCF-7-PKC- $\alpha$ cells transiently transfected with this reporter construct. The bars represent SEM. Each of these experiments was repeated with similar results.

growth rate with a higher percentage of cells in $\mathrm{S}$ phase, anchorage-independent proliferation, a transition from an epithelial to a mesenchymal-like morphology, loss of estrogen receptor content, and increased tumor formation with metastatic capacity in nude mice. The transition to a more mesenchymal appearance, the corresponding increase in vimentin expression, a high $S$ phase fraction, and the loss of estrogen receptor expression with the attendant decrease in levels of the pS2 mRNA transcripts occurring in the MCF-7-PKC- $\alpha$ cell are observed in breast cancer patients with a more malignant course and less favorable prognosis $(21-23,27,28)$. Interestingly, mRNA transcripts for cathepsin D were markedly reduced in the MCF$7-\mathrm{PKC}-\alpha$ cell. While cathepsin D is an estrogen-responsive gene, clinical studies have demonstrated that cathepsin D expression is a poor prognostic indicator, with high levels predicting a poor clinical outcome in breast cancer patients (29). Thus, the reduced cathepsin D content in MCF-7-PKC- $\alpha$ cells seems at odds with the obvious progression of this cell to a more aggressive phenotype. Perhaps explaining this discrepancy is the finding that in clinical specimens the cathepsin D content may be derived from cells other than mammary epithelium cells (30). Thus, the MCF-7-PKC- $\alpha$ cell seems to recapitulate a very similar phenotype to that found in more aggressive lesions derived from patients with breast cancer. This close recapitulation of phenotypic characteristics substantiates a possible role for alterations in the PKC pathway in modulating the in vivo progression of human breast cancer and suggests the potential usefulness of the MCF-7-PKC- $\alpha$ cell in screening antineoplastic agents used for treating advanced forms of breast cancer.

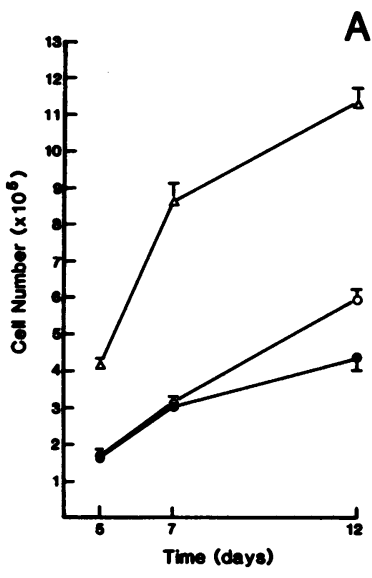

A

Figure 6. MCF-7-PKC- $\alpha$ cells exhibit a higher proliferative rate than MCF-7 cells. ( $A$ ) MCF-7 (O-O), vector-transfected ( $\bullet \bullet)$, and MCF-7-PKC- $\alpha(\Delta-\Delta)$ cells were plated in 24-well plates at 7.5 $\times 10^{3} / \mathrm{ml}$, and total cell number was assessed at various times (abscissa) after plating. $(B)$ In a separate experiment, the growth of nonadherent MCF-7 $(O-O)$ and MCF-7-PKC- $\alpha(\Delta--\Delta)$ cells is shown. The number of nonadherent cells is expressed as a percentage of total cells. Each point is derived from six separate samples. These experiments were repeated on several occasions with similar results.

A negative correlation between PKC activity and estrogen receptor status in breast cancer has been previously noted (4, $5)$. The mechanism responsible for this association has yet to be fully elucidated. Exposure of breast cancer cells to phorbol esters that both activate and downregulate PKC activity results in a significant reduction in mRNA transcripts of the estrogen receptor (30-32). Given that the status of alterations within the PKC pathway was not evaluated in these investigations (3133 ), the specific mechanism by which phorbol esters interacted with the PKC pathway to decrease the level of mRNA transcripts for the estrogen receptor gene is unclear. Thus, estrogen receptor expression could be negatively modulated by phorbol ester-induced activation of a specific PKC isoform(s) or because of downregulation of an isoform( $\mathrm{s}$ ) necessary for maintenance of estrogen receptor mRNA levels. In the MCF-7-PKC$\alpha$ cell, the predominant alterations in the PKC pathway were an increase in the conventional $\alpha$ and $\beta$ isoforms. It is tempting to speculate that the increased content of these isoforms led directly to an enhanced basal kinase activity, which in turn activated a cascade that decreased content of estrogen receptor mRNA transcripts. Given the increased level of PKC- $\alpha$ in the estrogen receptor-negative MCF-7-PKC- $\alpha$ cell and the increased PKC- $\alpha$ levels with a reduction in PKC- $\beta$ content in the estrogen receptor-negative, multidrug-resistant (MDR) MCF7-MDR cells (33), a role for PKC- $\alpha$ in negatively modulating estrogen receptor expression seems possible. Obviously, further studies will need to be undertaken to prove such a hypothesis.

The significant morphologic alterations and higher degree of phenotypic transformation observed in the MCF-7-PKC- $\alpha$ cell contrast with the MCF-7-MDR clones that also overexpress PKC- $\alpha$. In the MCF-7-MDR subclones, PKC- $\alpha$ overexpression, relative to parental MCF-7 cells, is at least as much as or greater than that seen in MCF-7-PKC- $\alpha$ cells (34). The lack of similar morphologic and proliferative alterations in MCF-7-MDR cells suggests that PKC- $\alpha$ may not be directly responsible for the entirety of the changes observed in the MCF- 


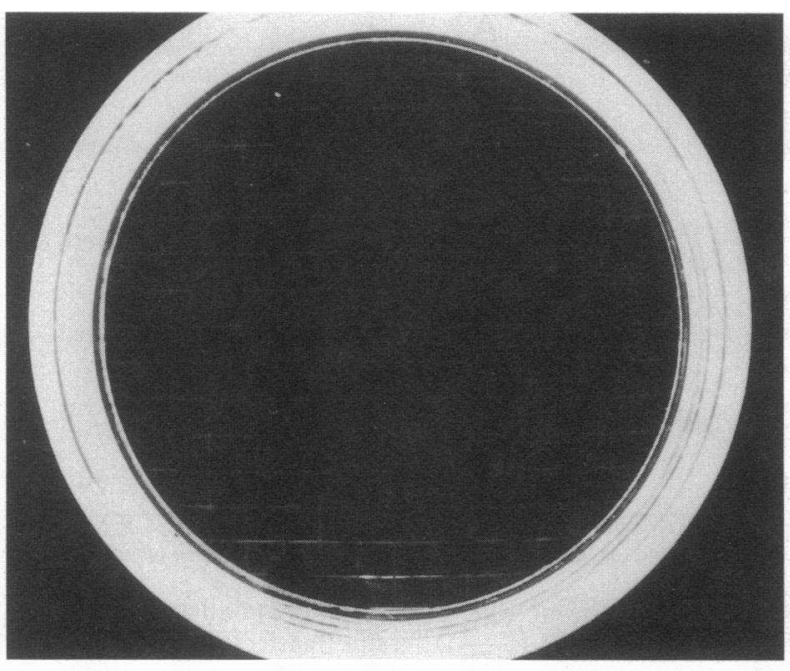

Cells:

Colonies: $(\bar{x} \pm$ SEM $)$

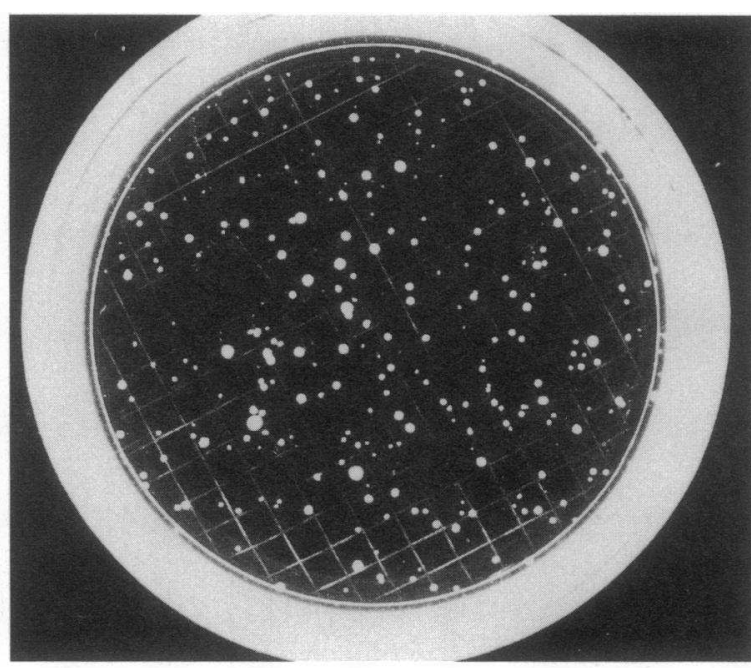

MCF-7-PKC $\alpha$

Figure 7. Anchorage-independent growth of MCF-7-PKC- $\alpha$ cells. Growth in soft agar of vector-transfected and MCF-7-PKC- $\alpha$ cells was performed as described in Methods. A colony was defined as a group of $>50$ cells. Colony growth is expressed as $X \pm$ SEM, $n=4$. This experiment was repeated with similar results.

7-PKC- $\alpha$ cells. Possibly explaining this discrepancy are differences in expression of other PKC isoforms in the MCF-7-PKC$\alpha$ and MCF-7-MDR cells. In MCF-7-MDR cells, PKC- $\epsilon$ is undetectable and significant decreases in the $\beta$ and $\delta$ isoforms are detected (34). In contrast, PKC- $\beta$ expression is enhanced, levels of PKC- $\delta$ are only modestly decreased, and PKC- $\epsilon$ content is unchanged in MCF-7-PKC- $\alpha$ cells. In addition, content of PKC- $\eta$ is markedly decreased in MCF-7-PKC- $\alpha$ cells, and to our knowledge the status of this isoform in MCF-7-MDR has not yet been reported. The decreased PKC- $\eta$ content in MCF-7-PKC- $\alpha$ cells may be related to the less differentiated status of this breast epithelial cell. In other epithelial cell types, a positive correlation exists between the level of PKC- $\eta$ expression and a more differentiated epithelial phenotype (35). Thus, the dissimilar phenotypès displayed by MCF-7-PKC- $\alpha$ and MCF-7-MDR cells could result from the differences in the array of expression of other PKC isoforms or an interplay between the content of an individual PKC isoform or subfamily relative to that of another isoform or subfamily. Alternatively, other phenotypic alterations occurring in the MCF-7-MDR cell resulting from selection in doxorubicin could modify the response of this cell to the elevated levels of PKC- $\alpha$. This latter possibility is suggested by the finding that overexpression of PKC- $\alpha$ in an MCF-7 cell line that was clonally isolated on the basis of its resistance to doxorubicin was reported to proliferate at approximately the same rate as the parental MCF-7 cell (36).

An alternative explanation for the different phenotype expressed by the MCF-7-PKC- $\alpha$ cell is that exposure to G418

Table I. Tumorigenicity of MCF-7 and MCF-7-PKC- $\alpha$ Cells in Nude Mice

\begin{tabular}{|c|c|c|c|c|c|c|}
\hline \multirow[b]{2}{*}{ Inoculated cell type } & \multirow[b]{2}{*}{$\begin{array}{l}\text { Animals with } \\
\text { primary tumor }\end{array}$} & \multirow[b]{2}{*}{$\begin{array}{l}\text { Volume of primary } \\
\text { tumor }\end{array}$} & \multirow[b]{2}{*}{$\begin{array}{l}\text { Number of animals } \\
\text { with metastasis }\end{array}$} & \multicolumn{3}{|c|}{ Site of metastasis } \\
\hline & & & & Lung & $\begin{array}{l}\text { Lymph } \\
\text { nodes }\end{array}$ & $\begin{array}{l}\text { Perinephric } \\
\text { fat }\end{array}$ \\
\hline MCF-7 & $2 / 10^{*}$ & $<1 \mathrm{~m}^{3}$ & $0 / 10$ & $0 / 10$ & $0 / 10$ & $0 / 10$ \\
\hline MCF-7-PKC- $\alpha$ & $9 / 10^{\ddagger}$ & $3,383 \mathrm{~mm}^{3} \pm 937^{8}$ & $6 / 10^{\| 1}$ & $4 / 10^{\prime}$ & $2 / 7$ & $3 / 10$ \\
\hline
\end{tabular}

* Animals having either micro- or macroscopic primary tumors at 4 wk after inoculation with $10^{7}$ cells. ${ }^{\ddagger}$ The animal not exhibiting a primary tumor had cells inadvertently injected into the subcutaneous space. ${ }^{8} X \pm S E M ; n=9$; range: $630-7,344$ mm $^{3}$; vol was defined as the product of length $\times$ width $\times$ diameter in $\mathbf{m m}$. "In one mouse, the contiguous muscle was extensively invaded by the primary tumor. ${ }^{1}$ Metastases at all sites were microscopic in size. A denominator less than the 10 animals in each group indicated that the specific anatomic site was not examined in all animals. 


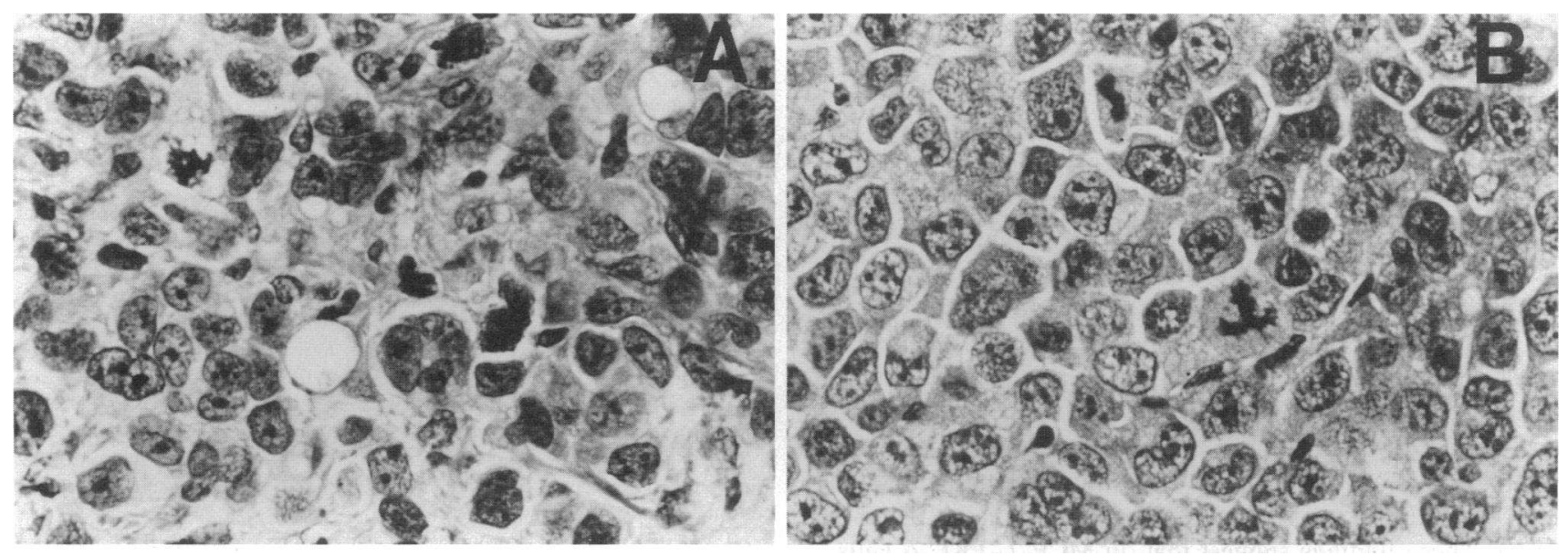

Figure 8. Histologic appearance of primary and metastatic lesions in nude mice. The primary tumors derived from mice injected with $7 \times 10^{6}$ parental MCF-7 and MCF-7-PKC- $\alpha$ cells for 4 wk are shown in $A$ and $B$, respectively.

resulted in selection of a neomycin-resistant cell with dramatically altered phenotypic characteristics that fortuitously overexpressed PKC- $\alpha$. While it is impossible to totally exclude this possibility, we believe that this scenario is unlikely. In mock or vector-transfected MCF-7 cells, we have not observed the selection of a cell with a MCF-7-PKC- $\alpha$-like phenotype. All G418-resistant cells from MCF-7 cells transfected with the neomycin resistance gene display an epithelioid appearance and have proliferative characteristics similar to parental MCF-7 cells. To our knowledge, examples of epithelial cells selected in G418 exhibiting MCF-7-PKC- $\alpha$-like phenotypic characteristics and concomitantly overexpressing PKC- $\alpha$ have not been reported. Thus, we believe that the phenotypic alterations occurring in the MCF-7-PKC- $\alpha$ cell were initiated by and are related to overexpression of PKC- $\alpha$.

While enhancing tumorigenicity in breast cancer cells, PKC$\alpha$ overexpression in murine fibroblasts and R6 cells inhibits proliferation and does not lead to transformation $(37,38)$. In hematopoietic cells, increases in the endogenous expression of PKC- $\alpha$ are associated with differentiation and cessation of growth (13). These divergent effects indicate that alterations in proliferation or differentiation induced by PKC- $\alpha$ overexpression are not an intrinsic property of this isoform, but are modulated by a dynamic interaction between cell-specific and maturationally related factors.

The mechanism by which overexpression of PKC- $\alpha$ alters morphology, enhances proliferation, increases tumorigenicity, and enhances metastatic potential remains to be determined. The increased mass of PKC- $\alpha$ would be predicted to increase the basal level of kinase activation. An enhanced basal level of kinase activation leading to increased phosphorylation of cellular substrates could induce the phenotype observed in the MCF$7-\mathrm{PKC}-\alpha$ cells. However, activation of PKC- $\alpha$ and other endogenous MCF-7 isoforms in the parental MCF-7 cell by either TPA or cell permeant diacylglycerol derivatives causes growth inhibition and differentiation (6-9). Thus, if an increase in the basal kinase activity was responsible for the observed changes in the MCF-7-PKC- $\alpha$ cell, then qualitatively different cellular responses are elicited by PKC-associated kinase activity stimulated by autocrine mechanisms or factors contained in serum (e.g., enhanced proliferation in MCF-7-PKC- $\alpha$ cells ). Alternatively, PKC- $\alpha$ overexpression may use a kinase-independent mechanism to elicit the phenotypic alterations observed in the MCF-7-PKC- $\alpha$ cell. A kinase-independent mechanism is supported by the temporal association of an increase in an underphosphorylated, kinase-inactive species of PKC- $\alpha$ in TPAtreated MCF-7 cells that have become desensitized to TPAinduced growth inhibition and have resumed proliferation (6). Therefore, PKC- $\alpha$ overexpression, whether via direct proteinprotein interactions or through a potential association with DNA by the cysteine-rich zinc fingers contained in the $C_{1}$ domain, has the theoretical potential to elicit signal transduction by a kinase-independent mechanism. Further studies with kinase-defective PKC- $\alpha$ mutants will be required to directly assess this hypothesis. Lastly, the phenotypic alterations in MCF-7-PKC$\alpha$ cells could be due in part to the high level of PKC- $\beta$ expression or reduction in PKC $-\eta$ and $-\delta$ content. Given the low level of $\beta$ expression in the parental cell, the signal transmitted by phorbol ester-induced activation of this isoform would be limited relative to that elicited by stimulation of the other TPAresponsive isoforms $(\alpha, \delta, \eta$, and $\epsilon)$. Thus, the biologic responses in TPA-treated parental MCF-7 cells would largely reflect activation of the $\alpha, \delta, \eta$, and $\epsilon$ isoforms. In MCF-7PKC $-\alpha$ cells, PKC $-\beta$ is highly overexpressed and would be predicted to contribute substantially to the basal level of kinase activity generated by PKC family members, while the contribution from PKC- $\eta$ and $-\delta$ would be less. As has been postulated by others $(1,2)$, differences in substrate specificity or subcellular distribution of PKC- $\beta$ could elicit qualitatively dissimilar cellular responses from those induced by the $\alpha, \delta, \eta$, and $\epsilon$ isoforms. Such differences between isoforms and the high degree of $\beta$ overexpression with the concomitant reduction in $\eta$ and $\delta$ expression in MCF-7-PKC- $\alpha$ cells could provide a possible mechanism explaining the divergent growth and phenotypic characteristics of parental MCF-7 and MCF-7-PKC- $\alpha$ cells.

The anchorage-independent growth of MCF-7-PKC- $\alpha$ cells demonstrates that anoikis that normally occurs upon detachment of epithelial cells from their matrix has been abrogated (39). A role for the PKC pathway in negatively modulating initiation of anoikis has been previously demonstrated in phorbol estertreated Madin-Darby canine kidney epithelial cells (39). Our results extend this observation regarding the inhibitory effects of the PKC pathway on induction of anoikis to mammary epithelial cells and suggest a potential role for the conventional PKC 
isoforms in regulating this process and its clinical counterpart, metastasis.

Expression of PKC- $\beta$ was enhanced in the MCF-7-PKC$\alpha$ cell. The human PKC- $\beta$ promoter contains multiple enhancer elements, including AP-1, AP-2, Sp1, E box, and octamer motifs, and also contains a sequence involved in transcriptional silencing (40). Interestingly, in K562 erythroleukemia cells, both basal and TPA-inducible expression of PKC- $\beta$ only require a sequence containing two Sp1 sites, an E box, and an octamer motif (40). Given that the AP-1 and AP-2 sites are not necessary for induction of this gene, it has been postulated that transcriptional activation occurs via a non-AP-1-dependent mechanism (40). Consistent with these results, our findings show that TPA treatment for a 24-h period does not increase expression of PKC- $\beta$ mRNA transcripts in parental MCF-7 cells (data not shown). These findings suggest that, in MCF-7-PKC- $\alpha$ cells, induction of PKC- $\beta$ expression occurs either as a direct effect of PKC- $\alpha$ overexpression by a kinase-independent mechanism or secondary to phenotypic changes associated with the MCF$7-\mathrm{PKC}-\alpha$ cell. The factors, and the level at which they act to modulate the endogenous expression of the $\beta$ isoform, are under investigation in our laboratories.

The clinical significance of these findings in the prognostic evaluation of malignant breast lesions and in developing novel therapeutic modalities seems promising. Assessing the level and array of specific PKC isoform expression in primary breast masses could be useful in gauging the metastatic potential and/ or biological aggressiveness of the lesion. Such information could be of use in determining the appropriate degree of radiation or chemotherapeutic intervention, especially in circumstances such as axillary node-negative disease. The ability of PKC- $\alpha$ overexpression to enhance proliferation and to induce a more biologically aggressive phenotype, either directly or indirectly via alterations in expression of other endogenous PKC isoforms, also indicates the potential promise of therapeutic modalities directed at inhibiting isoform( $\mathrm{s}$ ) expression or function. Currently, such methodology is available using antisense or ribozyme therapy directed against individual PKC isoforms or by downregulating PKCs with bryostatin-1 treatment (41, $42)$. Thus, these findings open exciting new possibilities that could improve the evaluation and treatment of patients with certain forms of breast cancer.

\section{Acknowledgments}

We wish to thank Nancy Hamm and June Long for expert assistance in preparation of this manuscript, Dr. Jack Brinn and Dr. Alvin Volkman (both from East Carolina University School of Medicine) for their advice on morphologic interpretations, Dr. John Bradfield and the Department of Comparative Medicine (East Carolina University School of Medicine) for assistance in performing the nude mice experiments, and Dr. Susan Rittling and Dr. Gerhardt Ryffel for providing the plasmids used in this study.

This work was partially supported by a National Institutes of Health grant (CA43023).

\section{References}

1. Nishizuka, Y. 1988. The molecular heterogeneity of protein kinase $\mathrm{C}$ and its implications for cellular regulation. Nature (Lond.). 334:661-665.

2. Parker, P., G. Kour, R. Marais, F. Mitchell, C. Pears, S. Stabel, and C. Webster. 1989. Protein kinase C: a family affair. Mol. Cell. Endocrinol. 65:111.
3. O'Brian, C., V. Vogel, S. Singletary, and E. Ward. 1989. Elevated protein kinase $\mathrm{C}$ expression in human breast tumor biopsies relative to normal breast tissue. Cancer Res. 49:3215-3217.

4. Borner, C., R. Wyss, R. Regazzi, U. Eppenberger, and D. Fabbro. 1987 Immunological quantitation of phospholipid $/ \mathrm{Ca}^{2+}$-dependent protein kinase of human mammary carcinoma cells: inverse relationships to estrogen receptors. Int. J. Cancer. 40:344-348.

5. Lee, S., J. Karaszkiewicz, and W. Anderson. 1992. Elevated level of nuclear protein kinase $\mathrm{C}$ in multidrug-resistant $\mathrm{MCF}-7$ human breast carcinoma cells. Cancer Res. 52:3750-3759.

6. Fabbro, D., R. Regazzi, S. Costa, C. Borner, and U. Eppenberger. 1986. Protein kinase $\mathrm{C}$ desensitization by phorbol esters and its impact on growth of human breast cancer cells. Biochem. Biophys. Res. Commun. 135:65-73.

7. Issandou, M., F. Bayard, and J. Darbon. 1988. Inhibition of MCF-7 cell growth by 12-0-tetradecanoylphorbol-13-acetate and 1,2 dioctanoyl-SN-glycerol: distinct effects on protein kinase C activity. Cancer Res. 48:6943-6950.

8. Kennedy, M., L. Presligiacoma, G. Tyler, W. May, and N. Davidson. 1992. Differentiation effects of bryostatin 1 and phorbol ester on human breast cancer cell lines. Cancer Res. 52:1278-1283.

9. Valette, A., N. Gas, F. Roubinet, M. Dupont, and F. Bayard. 1987. Influence of 12-0-tetradecanoylphorbol-13-acetate on proliferation and maturation of human breast carcinoma cells (MCF-7): relationship to cell cycle events. Cancer Res. 47:1615-1620.

10. Seynaeve, C., M. Stetler-Stevenson, S. Sebers, G. Kaur, E. Sausville, and P. Worland. 1993. Cell cycle arrest and growth inhibition by the protein kinase antagonist UNC-01 in human breast carcinoma cells. Cancer Res. 53:2081-2086.

11. Pears, C., G. Kour, C. House, B. Kemp, and P. Parker. 1990. Mutagenesis of the pseudosubstrate site of protein kinase C leads to activation. Eur. J. Biochem. 194:89-94.

12. McNeall, J., A. Sanchez, P. Gray, C. Chesterman, and M. Sleigh. 1989. Hyperinducible gene expression from a metallothionein promoter containing additional metal-responsive elements. Gene (Amst.). 78:81-88.

13. Ways, D., B. Messer, T. Garris, W. Qin, P. Cook, and P. Parker. 1992. Modulation of protein kinase $\mathrm{C} \epsilon$ by phorbol esters in the monoblastoid U937 cell. Cancer Res. 52:5604-5609.

14. Bradford, M. 1976. A rapid and sensitive method for the quantitation of microgram quantities of protein utilizing the principles of protein-dye binding. Anal. Biochem. 72:248-254.

15. Ways, D., P. Cook, C. Webster, and P. Parker. 1992. Effect of phorbol esters on PKC- $\zeta$. J. Biol. Chem. 267:4799-4805.

16. Yasuda, I., A. Kishimoto, S. Tanaka, M. Tominaga, A. Sakurai, and Y. Nishizuka. 1990. A synthetic peptide substrate for selective assay of protein kinase C. Biochem. Biophys. Res. Commuń. 166:1220-1227.

17. Chomczynski, P., and N. Sacchi. 1987. Single-step method of RNA isolation by acid guanidinium thiocyanate-phenol-chloroform extraction. Anal. Biochem. 162:156-159.

18. McCubrey, J., L. Steelman, G. Sandlin, R. Riddle, and D. Ways. 1990. Effects of phorbol esters on an interleukin-3-dependent cell line. Blood. 76:6372.

19. Klein-Hitpass, L., M. Schorpp, V. Wagner, and G. Ryffel. 1986. An estrogen-responsive element derived from the 5 ' flanking region of Xenopus vitellogenin A2 gene functions in transfected human cells. Cell. 46:1053-1061.

20. Heuijerjans, J., F. Pieper, F. Ramaekers, L. Timmermans, H. Kuijpers, H. Bloemendal, and W. Venrooij. 1989. Association of mRNA and elF-2 $\alpha$ with the cytoskeleton in cells lacking vimentin. Exp. Cell Res. 181:317-330.

21. Raymond, W., and A. Leong. 1989. Co-expression of cytokeratin and vimentin intermediate filament proteins in benign and neoplastic breast epithelium. J. Pathol. 157:299-306.

22. Raymond, W., and A. Leong. 1989. Vimentin: a new prognostic parameter in breast carcinoma? J. Pathol. 158:107-114.

23. Rio, M., J. Bellocq, B. Gairard, U. Rasmussen, A. Krust, C. Keohl, H Calderoli, V. Schiff, R. Renaud, and P. Chambon. 1987. Specific expression of the pS2 gene in subclasses of breast cancers in comparison with expression of the estrogen and progesterone receptors and the oncogene ERB Z. Proc. Natl. Acad. Sci. USA 84:9243-9247.

24. Westley, B., and H. Rochefort. 1980. A secreted glycoprotein induced by estrogen in human breast cancer cell lines. Cell. 20:353-362.

25. Muss, $H$., and T. Kute. 1982. Flow cytometry in the management of breast cancer. In High-Risk Breast Cancer: Diagnosis. J. Ragaz and I. Ariel, editors. Springer-Verlag, Berlin. 103-119.

26. Kurebayashi, J., S. McLeskey, M. Johnson, M. Lippman, R. Dickson, and F. Kern. 1993. Quantitative demonstration of spontaneous metastasis by MCF-7 human breast cancer cells cotransfected with fibroblast growth factor- 4 and $L a c Z$. Cancer Res. 53:2178-2187.

27. Bae, S., G. Arand, H. Azzam, P. Pavasant, J. Torri, T. Frandsen, and E. Thompson. 1993. Molecular and cellular analysis of basement membrane invasion by human breast cancer cells in Matrigel-based in vitro assays. Breast Cancer Res. Treat. 24:241-255.

28. Knight, W., R. Livingston, E. Gregory, and W. McGuire. 1977. Estrogen 
receptor as an independent prognostic factor for early recurrence in breast cancer. Cancer Res. 37:4669-4671.

29. Rochefort, H. 1990. Cathepsin D in breast cancer. Breast Cancer Res. Treat. 16:3-13.

30. Johnson, M., J. Torri, M. Lippman, and R. Dickson. 1993. The role of cathepsin D in the invasiveness of human breast cancer cells. Cancer Res. 53:873877.

31. Ree, A., B. Landmark, S. Walaas, H. Lahooti, L. Eikvar, W. Eskild, and V. Hansson. 1991. Down regulation of messenger ribonucleic acid and protein levels for estrogen receptors by phorbol ester and calcium in MCF-7 cells. Endocrinology. 129:339-344.

32. Saceda, M., C. Knabbe, R. Dickson, M. Lippman, D. Bronzert, R. Lindsey, M. Gottardis, and M. Martin. 1991. Post-transcriptional destabilization of estrogen receptor mRNA in MCF-7 cells by 12-0-tetradecanoylphorbol-13-acetate. J. Biol. Chem. 266:17809-17814.

33. Tzukerman, M., X. Zhang, and M. Pfahl. 1991. Inhibition of estrogen receptor activity by the tumor promoter 12-0-tetradecanoylphorbol-13-acetate: a molecular analysis. Mol. Endocrinol. 5:1983-1992.

34. Blobe, G., C. Sachs, W. Khan, D. Fabbro, S. Stabel, W. Wetsel, L. Obeid, R. Fine, and Y. Hannun. 1993. Selective regulation of expression of protein kinase C (PKC) isoenzymes in multidrug-resistant MCF-7 cells. J. Biol. Chem. 268:658664.

35. Osada, S., Y. Hashimoto, S. Nomura, Y. Kohno, K. Chida, O. Tajima, K. Kubo, K. Askimoto, H. Koizumi, Y. Kitamura, K. Suzuki, S. Ohno, and T. Kuroki 1993. Predominant expression of $\mathrm{nPKC}-\eta$, a $\mathrm{Ca}^{2+}$ independent isoform of protein kinase $\mathrm{C}$ in epithelial tissues, in association with epithelial differentiation. Cell Growth \& Differ. 4:167-175.

36. Yu, G., S. Ahmad, A. Aquino, C. Fairchild, J. Trepel, S. Ohno, K. Suzuki, T. Tsuruo, K. Cowan, and R. Glazer. 1991. Transection with protein kinase C- $\alpha$ confers increased multidrug resistance to MCF-7 cells expressing P-glycoprotein. Cancer Commun. 3:181-189.

37. Borner, C., I. Fillipuzzii, I. Weinstein, and R. Imber. 1991. Failure of wild-type or a mutant form of protein kinase $\mathrm{C}-\alpha$ to transform fibroblasts. Nature (Lond.). 353:78-80.

38. Cacace, A., S. Guadango, R. Krauss, D. Fabbro, and I. Weinstein. 1993. The epsilon isoform of protein kinase $\mathrm{C}$ is an oncogene when overexpressed in rat fibroblasts. Oncogene. 8:2095-2014.

39. Frisch, S., and H. Francis. 1994. Disruption of epithelial cell-matrix interactions induces apoptosis. J. Cell Biol. 124:619-625.

40. Obeid, L., G. Blobe, L. Karolak, and Y. Hannun. 1992. Cloning and characterization of the major promoter of the human protein kinase $\mathrm{C} \beta$ gene. $J$. Biol. Chem. 267:20804-20810.

41. Prendiville, J., D. Crowther, N. Thatcher, P. Woll, B. Fox, A. McGowan, N. Testa, P. Stern, R. McDermott, M. Potter, and G. Pettit. 1993. A phase one study of intravenous bryostatin 1 in patients with advanced cancer. Br. J. Cancer. 68:418-425.

42. Philip, P., D. Rea, P. Thavasu, J Carmichael, N. Stuart, H. Rockett, D. Talbot, T. Ganesan, G. Pettit, F. Balkwill, and A. Harris. 1993. Phase I study of bryostatin 1: assessment of interleukin 6 and tumor necrosis factor $\alpha$ induction in vitro. J. Natl. Cancer Inst. 85:1812-1818. 